\title{
Tests of Drills during Drilling Holes into Alloy Wheels
}

Ladislav Kyncl $^{1}$, Marek Sadílek ${ }^{1}$, Robert Čep ${ }^{1}$, Jana Petrů${ }^{1}$, Dana Stancekova ${ }^{2}$, Josef Procházka ${ }^{1}$, Pavel Nováček ${ }^{1}$

${ }^{1}$ Department of Machining and Assembly, VSB - Technical University of Ostrava, 70833 Ostrava. Czech Republic. E-mail: ladislav.kyncl.st@vsb.cz, marek.sadilek@vsb.cz, robert.cep@vsb.cz, jana.petru@vsb.cz, josef.prochazka.st@vsb.cz,pavel.novacek@.st@vsb.cz

${ }^{2}$ Zilina University on Zilina, Faculty of Mechanical Engineering, Departmenaof Machining and Manufacturing Technologies, Univerzitná 1, 01026 Zilina, Slovakia. dana.stancekova@fstroj.uniza.sk

This article is interested about drilling the holes to the alloy wheels. Tested were drills to drilling holes for screws and service holes. For screw holes was tested the three-stage drill with inserts from polycrystalline diamond. Drilled are two different diameters and the transition spherical or conical surface. The service holes were drilled with cemented carbide drill availible from Mapal labeled Mega-drill-Alu-180. During test, was modified the geometry of the drill and we watched what will be the effect of applied modification. Tested was seven variants of regrinding the drill. We evaluate the surface roughness, but also if the drill has the right position and not be pushed away from its axis. Finally was tested drill with three edges. This drill bit is from company Mapal labeled Tritan.

Keywords: drilling, drill, alloy wheels, aluminum alloy

\section{References}

[1] KLOSÍK, R. (2014). Racionalizace výroby vybraných součástí: diplomová práce. Ostrava: VŠB - Technická univerzita Ostrava, Fakulta strojní, Katedra obrábění a montáže, 50 s.

[2] CemeCon, CC AluSpeed®. Dostupné z: http://www.cemecon.cz/povlakovani/cc-aluspeed.aspx

[3] Značková maziva CZ. Dostupné z: http://www.znackovamaziva.cz/e-shop/prumyslove-oleje/prumysl/rezne-kapaliny/s-toolway-s-465-201/

[4] GRAEVE, I., HIRSCH, J. Wrought Aluminium Alloys. European aluminium association. Dostupné z: http://aluminium.matter.org.uk/content/html/eng/default.asp?catid=214\&pageid

[5] ANTON, H. (2008). Materiály pro řezné nástroje. MM publishing, s. r. o. s. 235. ISBN 978-80-254-2250-2

[6] MAPAL. Tritan-Drill. Dostupné z: http://www.mapal.com/cz/novinky/novinky-a-udalosti/tritan-drill/

[7] CROMODORA WHEELS s. r. o. Dostupné z: http://iszp.kr-moravskoslezsky.cz/assets/temata/ippc/files /cromodora---zarizeni-na-vyrobu-litych-hlinikovych-kol.pdf

[8] MAPAL. Mega-Drill_Alu. Dostupné z: http://www.mapal.com/fileadmin/00_PDFDateien/Kataloge/en/ MAPAL_Competence_Solid_carbide_tools_en.pdf

[9] ČEP, R., JANÁSEK, A., MARTINICKÝ B., SADÍLEK M. (2011) Cutting tool life tests of ceramic inserts for car engine sleeves. Tehnički vjesnik/Technical Gazette, No.2, Vol. 18, p. 203 - 209, 06/2011

[10] SADÍLEK, M., ČEP, R.; BUDAK, I., SOKOVIC, M. (2011) Aspects of Using Tool Axis Inclination Angle, Strojniški vestnik - Journal of Mechanical Engineering, vol. 57, no. 9, p. 681-688.

[11] SADÍLEK, M., ČEP, R., SADÍLKOVÁ, Z., VALÍČEK, J., PETŘKOVSKÁ, L. (2013) Increasing tool life in turning with variable depth of cut. Materiali in tehnologije/Materials and technology. vol. 47, no.2, pp.199-203, ISSN:1580-2949.

[12] JURKO, J., ZAJAC, J., ČEP R. (2006). Top trendy v obrábění 2. část-Nástrojové materiály. Žilina: MEDIA/ST Žilina, 193 s. ISBN 80-968954-2-7.

[13] VASILKO, K. (2007). Analytická teória trieskového obrábania. Prešov: COFIN Prešov, 338 s. ISBN 978-808073-759-7.

[14] BRYCHTA, J., ČEP, R., SADÍLEK, M., PETŘKOVSKÁ, L., NOVÁKOVÁ, J. (2007). Nové směry v progresivním obráběni. Ostrava: VŠB-TU Ostrava, Dostupné z: http://www.elearn.vsb.cz/archivcd/FS/NSPO

[15] BRYCHTA, J., ČEP, R., NOVÁKOVÁ, J., PETŘKOVSKÁ, L. Technologie II - 2. díl. Ostrava: VŠB - Technická univerzita Ostrava. 2008. s. 150. ISBN 978-80-248-1822-1

[16] VASILKO, K., SIMKULET, V. (2012). Phenomenon of Twist Drill. Manufacturing Technology, Vol. 12, No. 13, pp. 281-285. ISSN 1213-2489. 
[17] NOVAK, M. (2012). Surface with High Precision of Roughness after Grinding. Manufacturing Technology, Vol. 12, No. 12, pp. 66-70. ISSN 1213-2489.

[18] MANKOVA, I., VRABEL, M., KOVAC, P. Artificial Neural Network Application for Surface Roughness Prediction when Drilling Nickel Based Alloy. Manufacturing Technology, Vol. 12, No. 2, pp. 281-285. ISSN 12132489.

\section{Paper number: M2014103}

Copyright (C) 2014. Published by Manufacturing Technology. All rights reserved. 